\title{
Rectal cancer in Luxembourg : a national population-based data
} report, I988-1998

\author{
René Scheiden*1,2, Julien Sand ${ }^{2}$, Joseph Weber ${ }^{3}$, Philippe Turk ${ }^{4}$, \\ Yolande Wagener ${ }^{5}$ and Catherine Capesius ${ }^{2}$
}

Address: ${ }^{1}$ division of pathology, National Health Laboratory, Luxembourg, ${ }^{2}$ Morphologic Tumour Registry, Luxembourg, ${ }^{3}$ department of gastroenterology, Medical Center of Luxembourg, ${ }^{4}$ department of gastroenterology, Clinic St. Therese, Luxembourg and ${ }^{5}$ division of preventive medicine, National Health Direction, Luxembourg

Email: René Scheiden* - rmt_lu@hotmail.com; Julien Sand - julien.sand@cst.lu; Joseph Weber - weber.jos@chl.lu;

Philippe Turk - philippe.turk@cst.lu; Yolande Wagener - yolande.wagener@ms.etat.lu; Catherine Capesius - rmt_lu@hotmail.com

* Corresponding author

Published: 21 October 2003

BMC Cancer 2003, 3:27
Received: 27 March 2003

Accepted: 21 October 2003

This article is available from: http://www.biomedcentral.com/I47/-2407/3/27

(C) 2003 Scheiden et al; licensee BioMed Central Ltd. This is an Open Access article: verbatim copying and redistribution of this article are permitted in all media for any purpose, provided this notice is preserved along with the article's original URL.

\begin{abstract}
Background: Morphologic criteria which might help to support the need for a preventive strategy for early detection of rectal cancer were analysed. Population-based data on rectal adenomas with high-grade dysplastic changes $(n=199)$ and invasive adenocarcinomas $(n=912)$ registered by the national Morphologic Tumour Registry (MTR) and diagnosed in a central department of pathology in Luxembourg between 1988 and 1998 were considered.
\end{abstract}

Methods: The analysis concerned time trends in frequency, crude incidence, tumour-stage, the rectal "high-grade" adenoma/invasive adenocarcinoma-ratio and the survival rates. Histopathological tumour-stage parameters (UICC/AJCC, 1997) in a consecutive series of 64I resected rectal cancers and their relationship with the observed patient survival are investigated.

Results: The majority of invasive adenocarcinomas are diagnosed at a late stage (i.e. Stage II and III) into contrast with the highly significant increase $(355 \%)$ in frequency of rectal high-grade adenomas (Stage 0). During the two-time periods 1988-1992 and 1994-1998 Stage I and Stage IVcases decreased by II \% and $47 \%$ respectively. Tumour-stage correlates with prognosis. The rectal high-grade adenoma / invasive adenocarcinoma-ratio improved significantly over the last five years.

Conclusion: Over the study period, there has been a highly significant rise in the incidence of resected rectal adenomas with high-grade intraepithelial neoplasia. The ratio of early tumours to invasive cancers has risen while the numbers of colonoscopies and rectoscopies remained unchanged respectively decreased. As the number of advanced tumour-stages remained stable, mass-screening procedures focusing on the fifty to sixty age group should be reinforced.

\section{Introduction}

As described by the TNM-system and confirmed by many multivariate analyses the prognosis of patients after tumour-resection for cure (R0) of colorectal cancer (CRC) is predominantly influenced by the anatomical extend of cancer [1-9]. 
In view of a national CRC-screening pilot-project, the authors have collected descriptive epidemiological data of the rectal cancer (i.e. frequency, crude incidence, age distribution, age standardized incidence rates, tumour-stage, residual tumour tissue, number of the senior surgeons involved, number of colonoscopies realized, number of rectoscopies, mortality rates) for different time spans in the Grand-Duchy of Luxembourg (Western Europe).

Evaluating the data from the period 1988-1998, arguments and criteria to develop an alternative strategy for early detection of colorectal cancer in a defined area (Luxembourg) with a 'liberal' medical care system and without academic medical institutions have to be looked for.

\section{Methods}

Between January 1rst 1988 and December 311998 the Morphologic Tumour Registry (MTR) in Luxembourg registered 199 new cases of rectal "high-grade" adenomas and 912 new consecutive cases of invasive rectal adenocarcinomas in a population increasing from 374,900 in 1988 to 429,200 in 1998 , an average increase of $1.3 \%$ per year [10-12]. The registration of rectal high-grade adenomas and invasive adenocarcinomas diagnosed by 9 pathologists in the only department of pathology in the country is mandatory. In this study patients of all nationality living in Luxembourg were evaluated. Only new primary tumours were considered. Recurrent disease, synchronous or metachronous adenomas or adenocarcinomas, mesenchymal malignant tumours, epidermoid tumours of the anorectal junction, metastatic lesions and high-grade adenomas at the same site were excluded the latter being considered separately. The rectal cancers (RC) were removed by 45 senior surgeons.

Excluding invasive cancers diagnosed only by biopsy, there were 694 surgical specimens allowing an interpretation in function of the tumour depth of penetration of the rectal wall (pT) $[1-3,9,13]$. In analogy to the former original Dukes-System 641 surgical resection specimens permited an analysis in relation to the lymph node-status by the tumour-stage (Stage I to IV) supported by the Union International Contre le Cancer (UICC) and the American Joint Committee on Cancer (AJCC) $[1-4,14]$. So the stratification by stage (Table 1 ) required the exclusion of patients diagnosed by biopsy forceps only, patients who underwent only polypectomy without segmental resection or rectal amputation and patients with known preoperative non-surgical, debulking treatments. By this way an evaluation of our data in relation to the evaluable presence or absence of lymph nodes (i.e. polypectomy, transanal resection versus classic amputation) could be realized.

The R-classification was performed by conventional methods [3-9] and focused on the loco-regional extend. The different categories were defined as follows:

$\mathrm{Rx}=$ presence of residual tumour cannot be assessed; $\mathrm{R} 0=$ no residual tumour; $\mathrm{R} 1=$ microscopically residual tumour; R2 = macroscopically residual tumor [1].

To evaluate the survival rates in relation to the anatomical extent 203 patients with RC only diagnosed by biopsy without surgical resection had to be excluded previously and were subject of a separate analysis.

The histopathological diagnoses of all lesions were realized following the WHO-classification [15]. According to the WHO-recommandations, we defined "high-grade" adenomas as adenomas of tubular, villous or tubulo-villous histological type with high-grade intraepithelial neoplasia (i.e. dysplasia) $[15,16]$. This category includes, in analogy to the pTis-class or stage 0 of the TNM-System, cancer cells confined within the glandular basement membrane (intraepithelial) or lamina propria (intramucosal) with no extension through muscularis mucosa into submucosa [1-3]. The staging according to the TNM-classification was completed with the residual tumour status (R) $[1,2,7-9]$. Anatomically the rectum was defined as a $16 \mathrm{~cm}$ long segment between the ano-cutaneous line and the sigmoid colon.

Table I: Tumour-stage classifications and equivalences Dukes (1932) - TNM/UICC-AJCC (1987, 1992, 1997) 1-4,14

\begin{tabular}{|c|c|c|c|c|c|c|}
\hline DUKES & STAGE & TNM & & & & degree of tumour extension \\
\hline \multirow[t]{2}{*}{ A } & $\mathbf{I}$ & PTI & NO & MO & TI: & submucosa \\
\hline & & рT2 & NO & MO & T2: & muscularis propria \\
\hline \multirow[t]{2}{*}{$B^{*}$} & II & pT3 & NO & MO & T3: & perirectal tissue \\
\hline & & PT4 & NO & MO & T4: & others orangs or structures/visceral peritoneum \\
\hline \multirow[t]{3}{*}{$C^{*}$} & III & any $T$ & NI & MO & NI: & $\leq 3$ regional lymph nodes \\
\hline & & any $T$ & N2 & MO & N2: & $>3$ regional lymph nodes \\
\hline & IV & anyT & anyN & MI & MI: & distant metastasis \\
\hline
\end{tabular}

*Dukes B is a composite of better (T3NOMO) and worse (T4NOMO) prognostic groups, as is Dukes C (anyT NIMO and anyT N2M0) 
Patient survival was measured from the time of operation. As expected survival rates of the 1990's of the Luxembourgish population were not yet available the calculation of the relative survival rates was not possible. The observed survival rates were analysed in relation to curative resection (i.e. R0-cases) and without distinction of the R-status (R0, R1, R2, Rx included).

To compare our results with the data of other geographical European regions published by the WHO in "Cancer in five continents, volume VII" [17] the rectal cancers had to be added to the cancers of the rectosigmoidal junction.

The statistical evaluations included the chi-square test with a level of significance $p<0.05$ and the life-table survival analysis. The age-standardized incidence rates were calculated by the direct method, the standard error of the age-standardized rates by the Poisson approximation [18].

\section{Results}

The unequivocal histopathological diagnosis of 912 consecutive invasive rectal adenocarcinomas (RC) were provided from 203 samples obtained by biopsy only $(22.3 \%), 32$ total polypectomy specimens (3.5\%) and 677 surgical resection specimens (74.2\%). The latter allowed a stratification by stage according to the TNM (UICC/AJCC)-classification [1-4]. 641 of these patients with surgical treatment have had available survival follow-up data.

The 912 invasive RC concerned 517 males (56.7\%) and 395 females (43.3\%), the M/F-ratio being 1.3:1. The age distribution varied from 26 years to 95 years (mean: 68.9 years). The average, annual, all-ages incidence rate of rectum cancer in Luxembourg over the period 1988-1998 was 20.7 per 100,000 both gender together, for males 23.8 per 100,000 and for females 17.6 per 100,000 . The average, annual, age-standardized incidence rate (ASR) of rectum cancer (period 1988-1998) was 12.1 per 100,000 (12.1 +/- 0.4 with $95 \%$ confidence interval), for males 16.5 per 100,000 (16.5 +/- 1.1,95\% confidence interval) and for females 8.7 per $100,000(8.7+/-0.5,95 \%$ confidence interval).

The crude and age-standardized incidence rates in relation to gender, did not significantly decrease (Figure 1). The comparison of patients diagnosed in the 5 -year periods 1988-1992 and 1994-1998 revealed a slight decrease of the crude, age standardized incidence rates for both gender from 12.6 to 11.9 , for females from 7.7 to 7.5 and for males from 17.1 to 15.8 .

The time trend (1988-1998) of the invasive RC shows a non significant increase of the frequency $(\mathrm{p}=\mathrm{n} . \mathrm{s}$.). The total number of invasive RC rose from 89 cases in the year 1988 to 95 cases in 1998 . The number of RC in males grew from 56 to 58 and in females from 33 to 37 . Comparing the two five-year periods 1988-1992 and 1994-1998 there was a slight increase in the absolute number of all $\mathrm{RC}$ from 409 to 425 cases. The absolute number of $\mathrm{RC}$ in males grew from 226 to 240 cases, in females from 183 to 185 cases.

Figure 2 shows the age distribution of all patients with a morphologically confirmed invasive rectal adenocarcinoma $(\mathrm{n}=912) .5 .6 \%$ of the patients $(51 / 912)$ had less than 50 years of age, $15.9 \%$ between 50 and 60 years; $29.2 \%$ between 60 and 70 years; $31.3 \%$ between 70 and 80 years and $18 \%$ of the patients were 80 years and above.

Time trends in relation to the tumour-stages defined by the TNM-System (UICC/AJCC) are represented in Figure 3. During the two five-year periods 1988-1992 versus 1994-1998 there is an highly significant increase of diagnosed stage 0 i.e. high-grade adenomas by $355 \%$. Stage Icases decreased by $11 \%$ and Stage IV-cases by $47 \%$. Stage II-cases increased by $6.6 \%$, Stage III by $35 \%$.

At the same period (1988 to 1998) 199 new cases of rectal high-grade adenomas (Stage 0 ) have been diagnosed (Figure 4). If we compare the average of the rectal "high-grade adenoma / invasive adenocarcinoma - ratio" of the fiveyear periods 1988-1992 and 1994-1998 with a ratio $1: 12,4(33 / 409)$ versus $1: 2,8(150 / 425)$ there is a highly significant improvement in the last decade $(\mathrm{p}<0.001)$.

The overall observed survival rates of 912 patients with an invasive rectal adenocarcinoma, diagnosed by biopsy or polypectomy or surgical specimen and calculated by the actuarial method (life-table) with a $95 \%$ confidence interval (c.i.) stratified by years are:first year $74+/-3 \%$ (n = 673/912); second year $59+/-3 \%(n=536 / 912)$; third year $51+/-3 \%(\mathrm{n}=463 / 912)$; forth year $46+/-3 \%(\mathrm{n}=$ $424 / 912)$ and after five years $43+/-3 \%(n=396 / 912)$.

In Table 2 the observed survival rates of 641 invasive rectal adenocarcinomas stratified by the stage independent of the residual tumour status $(\mathrm{Rx}, \mathrm{R} 0, \mathrm{R} 1$ or $\mathrm{R} 2)$. Table 3 shows the stratification of the observed 5-year survival rates in relation to the stages TNM (UICC/AJCC) considering only the 488 patients operated for cure (R0).

( ${ }^{*}$ The analysis of the observed survival rates concerning the 203 patients with invasive rectal cancer diagnosed by biopsy-forceps only reveals that 112 patients survived 12 months and 20 patients died in the first month, 43 within the next 6 months and 28 in the period from the 6 th to the 12 th month. The age distribution of these patients shows 


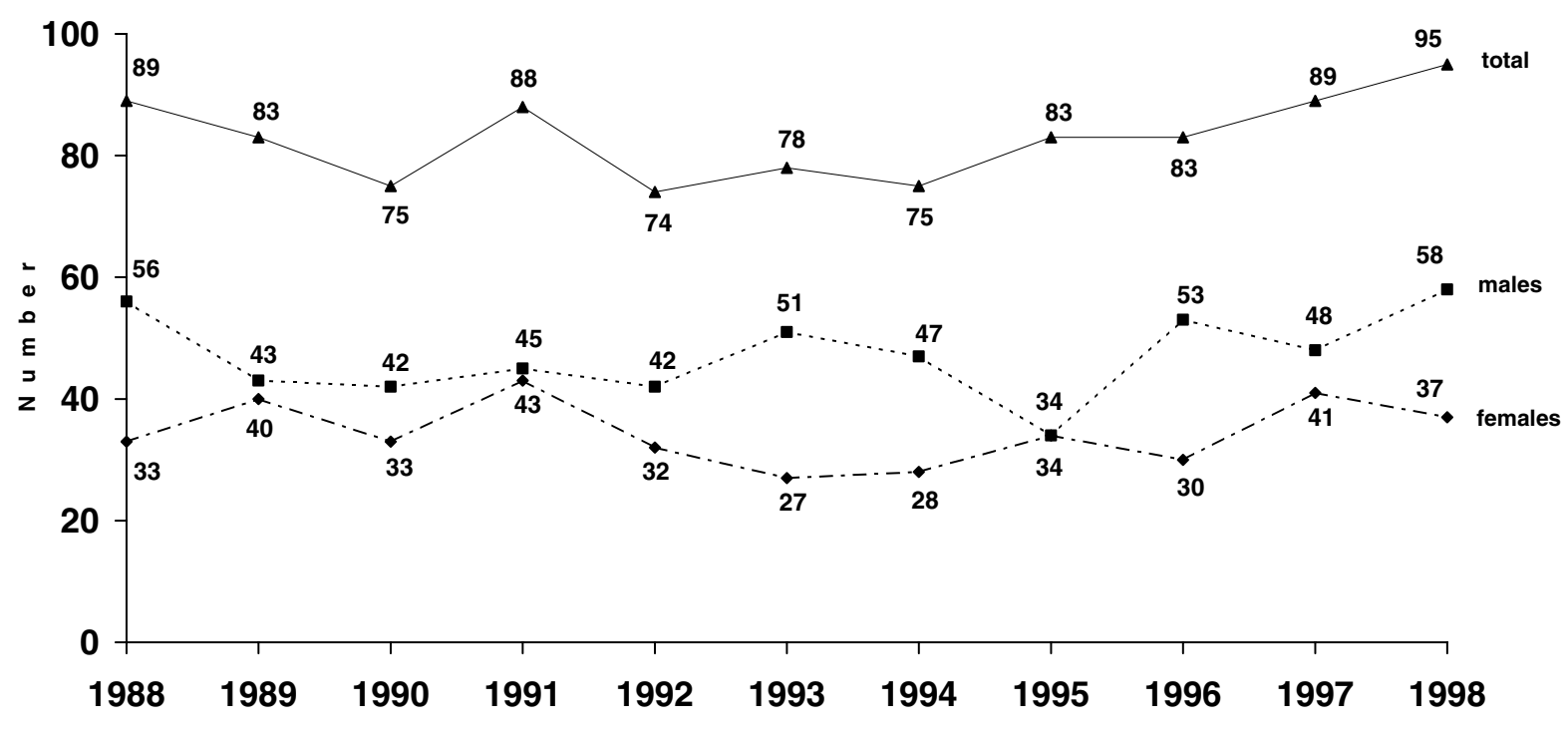

Figure I

Frequency of new invasive adenocarcinomas ( $n=912$ cases) Period 1988-1998.

that 13 had less than 50 years, 121 were aged between 50 and 79 years and 69 patients had more than 80 years.)

Table 4 documents the world age-standardized incidence rates (ASR/W) of invasive rectal adenocarcinomas in the Luxembourgish population (females and males) in comparison to other European countries not selected at random but for geographical proximity or populationdensity or socio-economic reasons.

To exclude an influence of changing colonoscopic diagnostic procedures in Luxembourg we analysed the data gratefully made available by the National Health Fund (NHF) [19] over the 4-year period 1992-1995. As represented in table 5, there were a non significant decrease in the number of colorectal endoscopies, a non significant increase in the number of colonoscopies with biopsy examination whereas the number of rectoscopies decreased significantly.
The mortality rates by rectal cancer of the last 15 years (1984-1998) regrouped by 5-year periods are summarized in table 6[20]. In the 1980's the mortality rates for both gender decreased significantly, whereas in the 1990's they remained stable.

\section{Discussion}

The incidence and crude incidence rates of the invasive rectal adenocarcinomas in our series are comparable to those of the limitrophe countries [17]. Knowledge of the frequencies of rectal high-grade adenomas and of invasive adenocarcinomas over years in a defined population and area may provide essential informations and arguments for the design of a colorectal cancer prevention program [21]. Comparing two 5-year periods (1988-1992 and 1994-1998) in our series there are no significant changes over time nor of the number of newly diagnosed invasive rectal cancers ( 409 vs $425, \mathrm{p}=\mathrm{n} . \mathrm{s}$.) neither of their crude incidences (120.6/100,000 vs $117.1 / 100,000, p=n . s$.). A similar time trend has been described by Jessup et al. [22] 


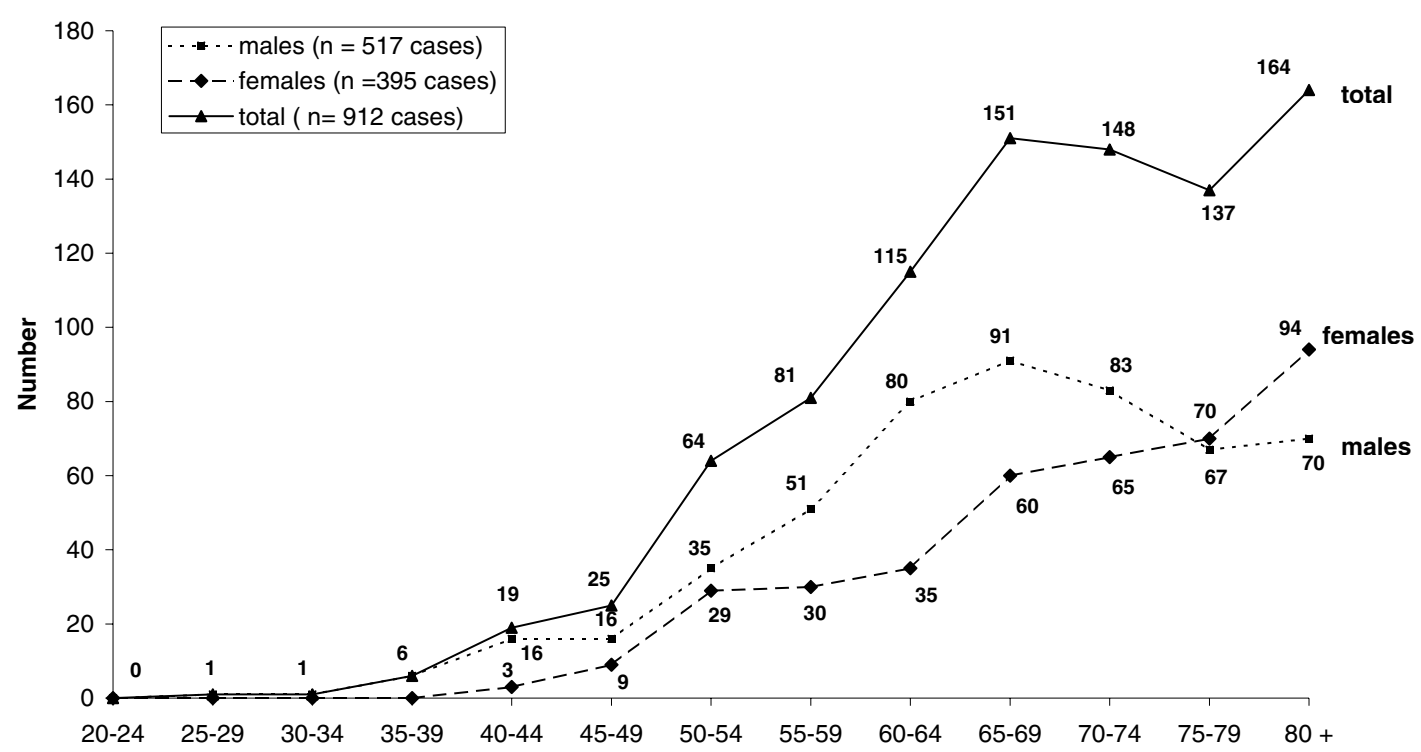

Figure 2

Invasive rectal adenocarcinomas $(n=912)$ - age distribution - period 1988-1998.

evaluating (National Cancer Data Base Report) a total of 98,537 rectal and rectosigmoid junction adenocarcinoma cases in the United States over the period 1985-1995.

The age distribution in our series reveals that mainly elderly patients suffer from rectal cancer, whereas only $5.5 \%$ (50/912) of the patients have less than 50 years [males $7.2 \%(37 / 516)$ and females 3.3\% (13/396)].

The comparison of the mortality rates of rectal cancer in Luxembourg over the last 15 years (Table 6) does denote a significant decrease $(\mathrm{p}<0.02)$ between the two first 5 year periods $(8.7 / 100,000$ period $1984-1988$ and $6.6 /$ 100,000 period 1989-1993) whereas during the two latter periods 1989 - 1993 and $1994-1998)$ there is no significant decrease ( $\mathrm{p}=\mathrm{n} . \mathrm{s}$.) [20]. It is generally accepted that stage at diagnosis is one of the strongest predictor of prognosis [23,24]. In our series $18.1 \%$ of the patients (116/641) were diagnosed as Stage I. This number is comparable to the results from 1005 rectal cancer cases diag- nosed between 1982 and 1987 and recorded by the tumour-registries of Mallorca (Spain), Côte d'Or (France) and Geneva (Switzerland) with $16 \%, 21 \%$ and $29 \%$ of Stage I-cases respectively [24]. Finn-Faivre et al. described in a series of 1978 patients with rectal cancer between 1978-1993 that the proportion of patients with Stage I cancer increased from $17.7 \%$ to $30.6 \%$ with a corresponding decrease in those with more advanced disease [25]. Unfortunately in Luxembourg the number of Stage Icases decreased by $11 \%$, that of advanced stages (i.e. Stage II and Stage III) increased by $6.6 \%$ and $35.0 \%$ respectively over the two 5-year periods 1988-1992 and 19941998. Thus it seemed that too many late stage cases (Stage II and Stage III) are diagnosed and that possibly the treatment outcome of rectal cancers in Luxembourg during the last decade has not improved significantly. This situation needs further investigations.

Survival analysis in relation to the data of the different patient-groups (i.e. all patients with morphologically ver- 


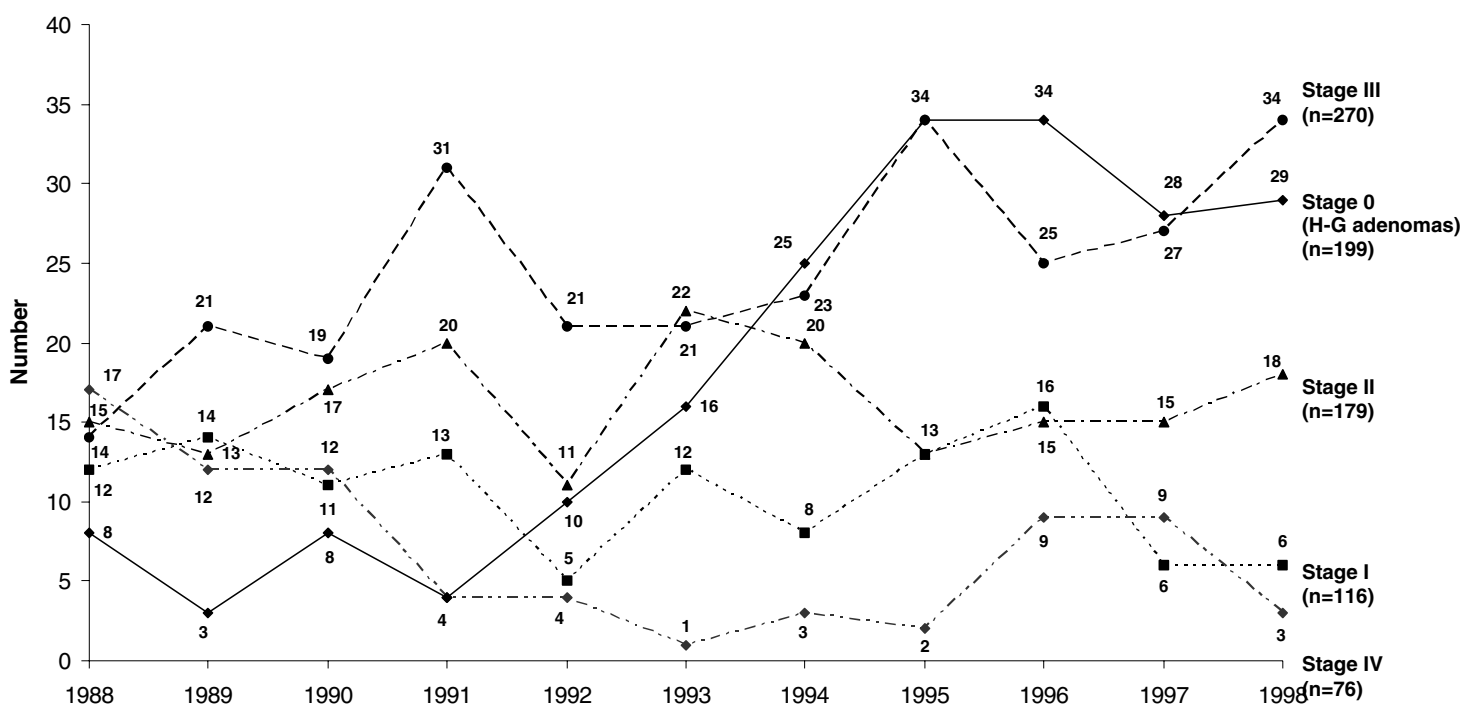

\section{Figure 3}

High-grade adenomas $(n=199$ cases $)$ and rectal invasive adenocarcinomas $(n=64 I$ cases $)$ by stage $($ TNM/UICC - AJCC, (997) $)^{3}$

ified rectal cancer diagnosis versus patients with polypectomy and rectal resection or amputation stratified by stage was undertaken $($ Table $2+3)$. The poorer prognosis correlates with the advanced tumour-stages and the residual tumour-classification, as described in the literature [79,22-27]. The highly significant increase in the detection of high-grade adenomas starting in 93 is due to the increased experience of the established endoscopists in Luxembourg since the late eighties. This has led to a better surveillance of patients presenting with low-grade adenomas and a better detection of high-grade adenomas. Public awareness is less relevant as public information campaigns have been carried out much later in Luxembourg. In addition, a certain number of patients might not have received additional adjuvant post-operative therapy. This is especially due for radiation therapy (in some Stage II and most Stage III patients), as this therapy was not available in Luxembourg until the late nineties and many patients were not able to travel abroad for personal or comorbidity reasons.
As summarized in Figure 4, we notice since 1992 a highly significant increase of the diagnoses of high-grade adenomas with a continuous improvement of the rectal highgrade adenoma / invasive adenocarcinoma-ratio although there was no significant increase of the number of gastroenterologists [19] or reimbursement of endoscopical explorations cost by the National Health Fund at least during the period 1992-1995 [19,21]. It could be admitted that this improved ratio will lead over the next decade to a falling incidence of invasive rectal cancer.

The improvement of the adenoma/adenocarcinoma-ratio over time is an index of better quality of the endoscopic explorations. This is due mainly because of two reasons: first, the arrival of a new generation of better trained endoscopists in the late eighties and secondly, a better understanding of the preventive indications for endoscopies by the practitioner as well as the general population. 
*diagnoses by biopsy only are included; $\square$ High-Grade Adenomas $\mathbf{n}$ invasive Adenocarcinomas

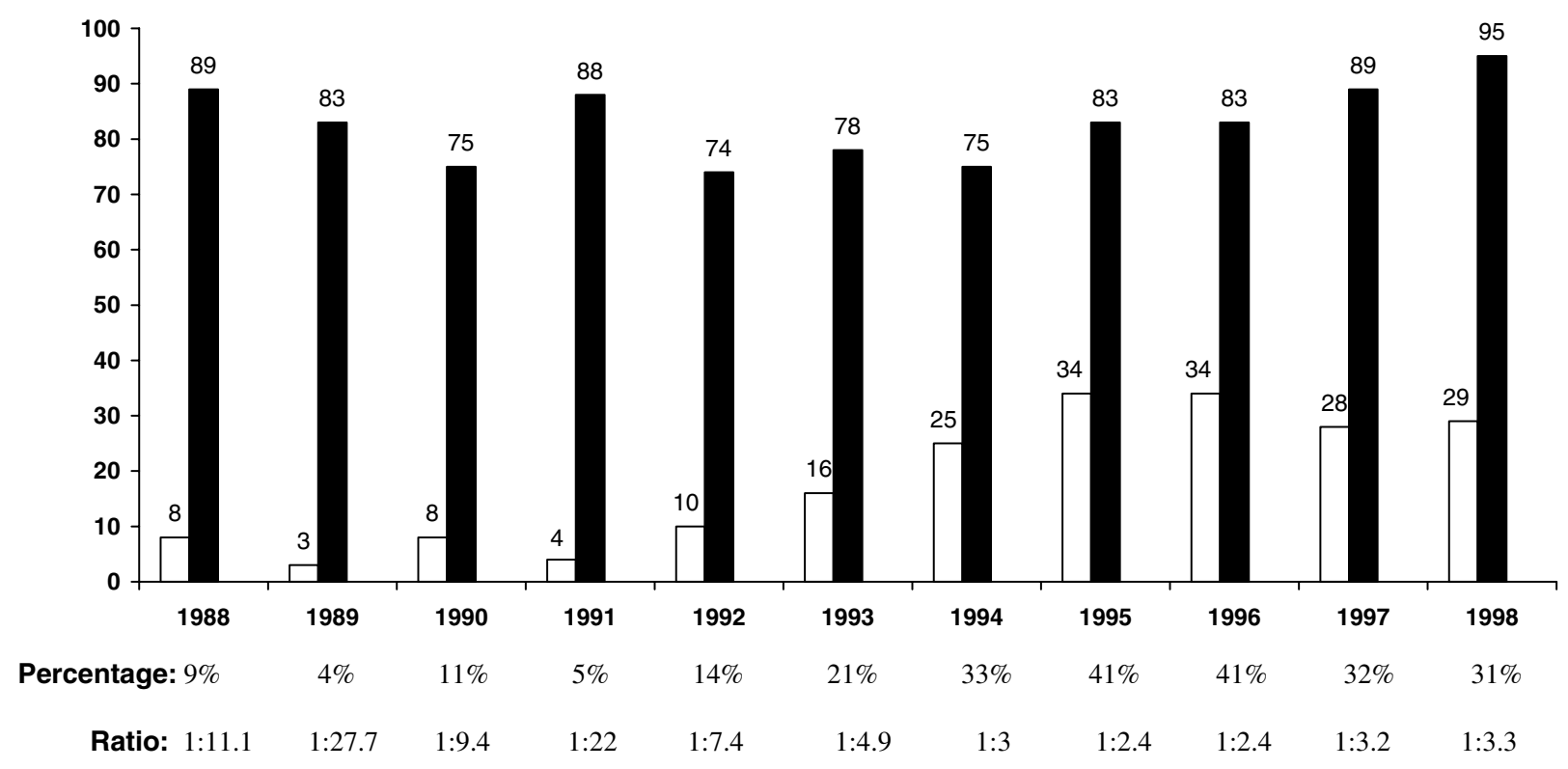

Figure 4

Rectal high-grade adenoma / invasive adenocarcinoma-ratio: time-trend from 1988 to $1998 ;$ males and females; $\mathrm{n}=199 * / 912$ casest

Table 2: Rectal adenocarcinomas: observed survival rates calculated by the actuarialmethod (95\% confidence interval) by stage (TNM/ UICC, 1997) [3] without distinctionof the R-status $(R 0, R I, R 2, R x) n=64 I$ cases

\begin{tabular}{|c|c|c|c|c|c|c|c|c|c|c|}
\hline & $\begin{array}{l}\text { Stage I-IV } \\
n=64 \mid(100 \%)\end{array}$ & & $\begin{array}{l}\text { Stage I* } \\
n=116(18.1 \%)\end{array}$ & & $\begin{array}{l}\text { Stage II* } \\
\mathrm{n}=179(27.9 \%)\end{array}$ & & $\begin{array}{l}\text { Stage III* } \\
n=270(42.1 \%)\end{array}$ & & $\begin{array}{l}\text { Stage IV* } \\
n=76(11.9 \%)\end{array}$ & \\
\hline I year & $78+/-3 \%$ & $(n=503)$ & $94+/-4 \%$ & $(n=109)$ & $88+/-5 \%$ & $(n=157)$ & $70+/-5 \%$ & $(n=188)$ & $64+/-11 \%$ & $(n=49)$ \\
\hline 2 years & $64+/-4 \%$ & $(n=408)$ & $90+1-6 \%$ & $(n=104)$ & $77+/-6 \%$ & $(n=137)$ & $50+/-6 \%$ & $(n=135)$ & $42 \%$ ** & $(n=32)$ \\
\hline 3 years & $54+/-4 \%$ & $(n=346)$ & $86+/-6 \%$ & $(\mathrm{n}=100)$ & $65+/-7 \%$ & $(n=117)$ & $39+1-6 \%$ & $(n=106)$ & $30 \% * *$ & $(n=23)$ \\
\hline 4 years & $49+1-4 \%$ & $(n=315)$ & $86+/-6 \%$ & $(n=100)$ & $58+/-7 \%$ & $(n=104)$ & $36+/-6 \%$ & $(n=97)$ & $18 \% * *$ & $(n=14)$ \\
\hline 5 years & $46+/-4 \%$ & $(n=292)$ & $81+/-7 \%$ & $(\mathrm{n}=94)$ & $55+/-7 \%$ & $(\mathrm{n}=98)$ & $34+/-6 \%$ & $(n=92)$ & $11 \% * *$ & $(\mathrm{n}=8)$ \\
\hline
\end{tabular}

* only surgical specimens ( $\mathrm{n}=64 \mathrm{I}$ cases) with available survival data ** standard error omitted sample being too small 
Table 3: Rectal adenocarcinomas - 5-year overall observed survival rates calculated by the actuarial (life-table) method ( $95 \%$ confidence interval) - curative resection (R0)*

5-year observed survival rates

\begin{tabular}{ccc}
\hline Stage (I-IV) & $\mathrm{n}=488 \operatorname{cases}(100 \%)$ & $53+/-4 \%(\mathrm{n}=259)$ \\
Stage I & $\mathrm{n}=110 \operatorname{cases}(23 \%)$ & $82+/-7 \%(\mathrm{n}=90)$ \\
Stage II & $\mathrm{n}=140 \operatorname{cases}(29 \%)$ & $62+/-8 \%(\mathrm{n}=87)$ \\
Stage III & $\mathrm{n}=190 \operatorname{cases}(39 \%)$ & $40+/-7 \%(\mathrm{n}=76)$ \\
Stage IV & $\mathrm{n}=48 \operatorname{cases}(10 \%)$ & $13+/-9 \%(\mathrm{n}=6)$
\end{tabular}

* excluded cases diagnosed by biopsy or polypectomy only

Table 4: Rectal cancer in the European Community: World age-standardized incidence rates [ASR(W)*]; $1988-1992$

\begin{tabular}{llll}
\hline MALES & & FEMALES & \\
\hline F/Bas-Rhin & 19.0 & D/Saarland & 10.9 \\
NL/Maastricht & 18.6 & DK/Denmark & 10.4 \\
L/Luxembourg & 17.6 & NL/Maastricht & 10.4 \\
D/Saarland & 17.3 & L/Luxembourg & 9.2 \\
DK/Denmark & 17.0 & UK/South Western & 9.0 \\
A/Tyrol & 14.8 & F/Bas-Rhin & 8.9 \\
UK/South Western & 14.2 & A/Tyrol & 8.9 \\
CH/St. Gallen & 14.1 & I/Parma & 8.8 \\
E/Basque Country & 13.5 & S/Sweden & 8.3 \\
IRL/Southern & 13.1 & CH/St. Gallen & 7.9 \\
I/Parma & 13.0 & IRL/Southern & 7.2 \\
S/Sweden & 12.1 & SF/Finland & 6.6 \\
SF/Finland & 10.5 & E/Basque Country & 6.4 \\
\hline
\end{tabular}

* Cancer incidence in five continents. Vol. VII period 1988-199217

Table 5: Time trend of the number of colorectal 'endoscopical' procedures in Luxembourg (period 1992-1995) 19

\begin{tabular}{|c|c|c|c|c|c|c|}
\hline & \multicolumn{2}{|c|}{$\begin{array}{l}\text { Total number of } \\
\text { Colo-rectal Endoscopies }\end{array}$} & \multicolumn{2}{|l|}{ Colonoscopies with biopsy } & \multicolumn{2}{|l|}{ Rectoscopies } \\
\hline & $n=30489$ & $\mathrm{n} / 10^{5 *}$ & $\mathbf{n}=|| 49 \mid\left(37.7 \%^{* *}\right)$ & $\mathrm{n} / 10^{5}$ & $\mathbf{n}=\mathbf{6 7 8 7}(22.3 \% * *)$ & $\mathrm{n} / 10^{5}$ \\
\hline 1992 & $n=7621$ & 1928.4 & $\mathbf{n}=\mathbf{2 6 9 9}\left(35.4 \%^{* *}\right)$ & 682.9 & $\mathbf{n}=1795(23.6 \% * *)$ & 454.2 \\
\hline 1993 & $n=7867$ & 1962.3 & $\mathbf{n}=2883(36.6 \% * *)$ & 719.1 & $\mathbf{n}=1819(23.1 \% * *)$ & 453.7 \\
\hline 1994 & $n=7590$ & 1866.7 & $\mathbf{n}=2962(39.0 \% * *)$ & 728.5 & $\mathrm{n}=1663(21.9 \% * *)$ & 409.0 \\
\hline 1995 & $n=74 I I$ & 1795.3 & $\mathbf{n}=\mathbf{2 9 4 7}(39.8 \% * *)$ & 713.9 & $\mathbf{n}=1510(20.4 \% * *)$ & 365.8 \\
\hline
\end{tabular}

*) number per 100,000 persons at risk **) \% in relation to all colorectal endoscopies

Table 6: Analysis of the mortality rates from all rectal adenocarcinomas of the last 15 years (1984-1998) ${ }^{20}$

\begin{tabular}{|c|c|c|c|c|}
\hline & Males & Females & both gender & P-value* \\
\hline | 984-1 988: & $9.7 / 10^{5}$ & $7.8 / 10^{5}$ & $8.7 / 10^{5}$ & $p<0.02$ \\
\hline |989-1993: & $6.5 / 10^{5}$ & $6.6 / 10^{5}$ & $6.6 / 10^{5}$ & $p=n . s$. \\
\hline 1994-1998: & $6.2 / 10^{5}$ & $6.4 / 10^{5}$ & $6.3 / 10^{5}$ & \\
\hline
\end{tabular}

\footnotetext{
* level of significance 0.05
} 


\section{Conclusion}

The classic mass-screening programmes of colorectal cancers being controversially discussed, it nevertheless seems to be necessary to reinforce early detection by means of a systematic information of physicians and patients focusing on the fifty and sixty age group in view to decrease the number of advanced tumour-stage.

For the future, the actual adenoma/adenocarcinoma-ratio of 1:2,9 (average of the last 5 years) will be accepted as "golden standard" to assess the quality of an "Endoscopic National Program of Prevention of colo-rectal cancers" in collaboration with the governmental authorities.

\section{Author's contributions}

All authors (RS, JS, JW, PT, YW, CC) collaborated intensely on all aspects of the manuscript, from research design to data preparation to presentation. RS and JS wrote and all authors approved the final manuscript.

\section{Acknowledgments}

We thank Mrs Martine Becker, Mrs Mireille Braun and Mrs Margot Poos for their helpful assistance during the preparation of this manuscript.

The study received financial support from the national Morphologic Tumour Registry (RMT a.s.b.l.). The opinions stated in this document are those of the authors and do not necessarily represent the official position of the RMT.

\section{References}

I. Hermanek $P$ and Sobin LH: TNM classification of malignant tumours, UICC, $2^{\text {nd }}$ revision. Berlin Heidelberg New York: Springer 41992.

2. Hermanek P, Henson DE, Hutter RVP and Sobin LH: UICC TNM supplement 1993. A commentary on uniform use. Berlin Heidelberg New York: Springer 1993.

3. Sobin $\mathrm{LH}$ and Wittekind $\mathrm{CH}$ : TNM classification of malignant tumours, UICC. New York, Chichester, Weinheim, Brisbane, Singapore, Toronto: Wiley-Liss 51997.

4. Fleming ID, Cooper JS, Henson DE, Hutter RVP, Kennedy BJ, Murphy GP, O'Sullivan B and Yarbro JW: AJCC Cancer Staging Manual,. Philadelphia: Lippincott 1997.

5. Hermanek P: Long term results of a German prospective multicenter study on colorectal cancer. In Recent advances in management of digestive cancers Edited by: Takahashi T. Berlin Heidelberg New York: Springer, 1993.

6. Michelassi F, Block GE, Vannucci L, Montag A and Chappell R: A 5-to 2I-year follow-up and analysis of 250 patients with rectal adenocarcinoma. Ann Surg 1988, 208:379-387.

7. Deans GT, Parks TG, Rowland BJ and Spence RA: Prognostic factors in colorectal cancer. Br J Surg 1992, 79:608-6/3.

8. Hermanek P and Sobin LH: Colorectal cancer. In Prognostic factors in cancer UICC Edited by: Hermanek P, Gospodarowicz MK, Henson DE, Hutter RVP, Sobin LH. Berlin Heidelberg New York: Springer; 1995.

9. Hermanek $P$ and Wittekind $C$ : Residual tumour (R) classification and prognosis. Semin Surg Oncol 1994, 1 0:12-20.

10. Capesius C, Scheiden R, Groff P, Kanz R, Juchem JP and Wehenkel Cl: Nouveaux cas de cancer au Luxembourg - Monographies des années I98I - 1982 - | 983 - 1984 - 1994 - 1995 - I 996 1997 - 1998. Luxembourg: Registre Morphologique des Tumeurs au Grand - Duché de Luxembourg 1997 [http://www.cancer-registry.lu].

II. Capesius C, Scheiden R, Groff P, Kanz R, Schneider F and Wehenkel $\mathrm{Cl}$ : Nouveaux cas de cancer au Luxembourg - Monographies des années 1985 - 1986 - 1987 - 1988 - 1989 - 1990 - | 991 1992 - 1993. Luxembourg: Registre Morphologique des Tumeurs au Grand-Duché de Luxembourg 1997 [http://www.cancer-registry.lu].
12. STATEC: Données démographiques 1988-1998. Luxembourg: Service central de la statistique et des études économiques 1999.

13. Fielding LP, Arsenault PA, Chapuis PH, Dent O, Gatright B, Hardcastle JD, Hermanek P, Jass JR and Newland RC: Clinico-pathological staging for colorectal cancer: an International Documentation System (IDS) and an International Comprehensive Anatomical Terminology (ICAT). J Gastroenterol Hepatol I99I, 6:325-344.

14. Dukes CE: The classification of cancer of the rectum. J Pathol Bacteriol 1932, 35:323-32.

15. Jass JR and Sobin LH: Histological typing of intestinal tumours. WHO - Intestinal Histological Classification of Tumours. Berlin Heidelberg New York Tokyo: Springer 21989.

16. Hamilton SR, Vogelstein B, Kudo S, Riboli E, Makamura S, Hainaut $P$, Rubio CA, Sobin LH, Fogt F, Winawer SJ, Goldgar DE and Jass JR: Carcinoma of the colon and rectum. In World Health Organization, Classification of Tumours, Pathology and Genetics, Tumours of the Digestive System Edited by: Hamilton SR, Aaltonen LA. Lyon: IARC; 2000:103-143.

17. Parkin DM, Whelan SL, Ferlay J, Raymond L and Young J: Cancer Incidence in Five Continents. Volume VII. Lyon: IARC Scientific Publications NRI 43; 1997.

18. Boyle P and Parkin DM: Statistical methods for registries. In Cancer registration, principles and methods Edited by: Jensen OM, Parkin DM, Mac Lennan R, Muir CS, Skeet RG. Lyon: IARC; 1991:126-158.

19. Kieffer R, Juchem JP and Feider J: Nombre de rectoscopies et colonoscopies avec et sans biopsies, années 1992 - 1995. Luxembourg: Union des Caisses de Maladie 1998.

20. Hansen-Koenig D, Schanck JM and Roulleaux M: Statistiquesdes causes de décès, années 1984 - 1998. Luxembourg:Direction de la Santé, Ministère de la Santé 1984.

21. Scheiden R, Sand J, Pandin M, Wagener Y and Capesius C: Colorectal high-grade adenomas: incidence, localization and adenoma-adenocarcinoma ratio in a retrospective and comparative population-based study of 225 consecutive cases between 1988 and 1996. Int J Colorectal Dis 2000, 15:29-34.

22. Jessup JM, Stewart AK and Menck RM: The National Cancer Data Base Report on Patterns of Care for Adenocarcinoma of the Rectum, 1985-1995. Cancer 1998, 83:2408-18.

23. Roncucci L, Fante R, Losi L, Di Gregorio C, Micheli A, Benatti P, Madenis N, Ganazzi D, Cassinadri MT, Lauriola P and Ponz de Leon M: Survival for colon and rectal cancer in a population-based cancer registry. Eur J Cancer 1996, 32A(2):295-302.

24. Monnet E, Faivre J, Raymond L and Garau J: Influence of stage at diagnosis on survival differences for rectal cancer in three european populations. Br J Cancer 1999, 8I:463-468.

25. Finn-Faivre C, Maurel J, Benhamiche AM, Herbert C, Mitry E, Launoy $G$ and Faivre J: Evidence of improving survival of patients with rectal cancer in France: a population-based study. Gut 1999, 44:377-381.

26. Henson DE and Gloeckler-Ries LA: On the estimation of survival. Semin Surg Oncol 1994, 10:2-6.

27. Newland RC, Dent OF, Chapuis PH and Bokey EC: Clinicopathologically diagnosed residual tumor after resection for colorectal cancer. Cancer 1993, 72:1536-1542.

\section{Pre-publication history}

The pre-publication history for this paper can be accessed here:

http://www.biomedcentral.com/1471-2407/3/27/prepub 